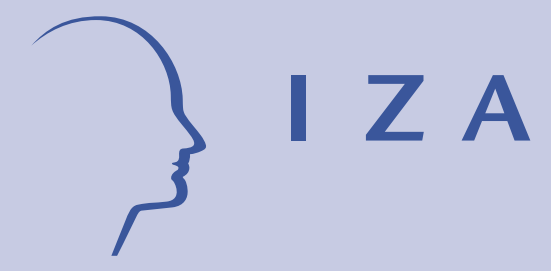

IZA Policy Paper No. 31

The Toll Index:

Innovation-based Economic Telemetry

Nikos Askitas

Klaus F. Zimmermann

October 2011

Forschungsinstitut zur Zukunft der Arbeit Institute for the Study of Labor 


\title{
The Toll Index: \\ Innovation-based Economic Telemetry
}

\author{
Nikos Askitas \\ IZA \\ Klaus F. Zimmermann \\ IZA and Bonn University
}

Policy Paper No. 31

October 2011

\author{
IZA \\ P.O. Box 7240 \\ 53072 Bonn \\ Germany \\ Phone: $+49-228-3894-0$ \\ Fax: +49-228-3894-180 \\ E-mail: iza@iza.org
}

The IZA Policy Paper Series publishes work by IZA staff and network members with immediate relevance for policymakers. Any opinions and views on policy expressed are those of the author(s) and not necessarily those of IZA.

The papers often represent preliminary work and are circulated to encourage discussion. Citation of such a paper should account for its provisional character. A revised version may be available directly from the corresponding author. 
IZA Policy Paper No. 31

October 2011

\section{The Toll Index: Innovation-based Economic Telemetry}

We present the operationalized Toll Index, which is a new type of early indicator for the German business cycle. We present the basic idea and document the power of the indicator for the purpose of nowcasting. The data will be regularly available at the IDSC, the data bank center of IZA and will be accessible there through the homepage. We further emphasize several policy recommendations regarding data.

JEL Classification: C82, E01, E32

Keywords: nowcasting, toll index, MAUT, economic telemetry, secondary data use

Corresponding author:

Nikos Askitas

IZA

P.O. Box 7240

53072 Bonn

Germany

E-mail: askitas@iza.org 


\section{The Nowcasting Deficit}

In a recent New York Times ${ }^{1}$ article written in the midst of the recent financial turmoil which had already caused financial markets to plummet world-wide it was mentioned that the much anticipated US government announcement on the growth rate of the US economy "has been off the mark over the period from 1983 to 2009 by an average of 1.3 percentage points, compared with more fully analyzed figures released years later, according to federal data”. It is mentioned therein that the US government had estimated the growth rate in the first quarter of 2009 to be equal to $1.8 \%$ in May, $1.9 \%$ in June and finally $0.4 \%$ in the most recent vintage of the same estimate (published in mid August). In other words the government started with the announcement of a moderate recovery and ended with announcing the "brink of a double dip recession". In the meantime, of course, financial markets, policy makers and the economy at large were operating using the wrong numbers.

\section{The German Case}

In Germany (and we suspect in the rest of the world) the situation is no different. In Askitas \& Zimmermann (2011) which is forthcoming this year in the Journal of Forecasting we show that in the time interval between January 2008 and July 2010 the German Production Index was off the mark by an average of $2.14 \%$ whereas the new Toll Index (TI) they propose in the paper was of the mark by less than $0.23 \%$ in the same time interval.

Table 1 below shows us what happened with the German Production Index of the last precrisis month: August 2008. It took 6 months for the value to be revised to the number we accept today and the revision was $-4.86 \%$ of the original preliminary value. This is a common phenomenon which is explained by the fact that economists and governments alike have not been

paying the proper attention to measurement issues but also that we have not yet used the technological advances in our data collection.

\footnotetext{
${ }^{1}$ http://www.nytimes.com/2011/08/17/business/economy/raw-data-on-economicgrowth-paints-fuzzy-picture.html?_r=3
} 
Table 1: Revisions of the German Production Index (with construction) for August 2008.

\begin{tabular}{|l|l|l|l|l|l|l|}
\hline Pub. Date & $10 / 8 / 08$ & $11 / 7 / 08$ & $12 / 8 / 08$ & $1 / 9 / 09$ & $2 / 6 / 09$ & $3 / 12 / 09$ \\
\hline Revision & 107 & 106.9 & 106.9 & 107 & 107 & 101.8 \\
\hline \multicolumn{7}{|l|}{ Source: GERDA (German Real-time Data) Deutsche Bundesbank } \\
\hline
\end{tabular}

\section{The Toll Index: a Concept of Nowcasting}

Nowcasting tells us what happens now. The Toll Index ${ }^{2}$ is an early indicator for the German business cycle introduced in Askitas \& Zimmermann (2011). It is based on German highway MAUT system data, where traffic data on the road transportation of goods are recorded. Owing to the systems innovative technology the data have some very attractive properties such as a short publication lags and insignificant revisions.

The informational value of the Toll Index is shown in Askitas \& Zimmermann (2011) in two ways: first an econometric model based on MAUT data from 2007-2009 outperforms standard benchmark time-series ARMA and AR models in forecasting the German Production Index. It is worthwhile noting that the benchmark models are trained on data which go back to 1991 (i.e. they have a severe starting advantage for the quality of predictions vs. the Toll Index) and that the paper uses the time 1/2010-7/2011 as the out of sample interval.

Second, the paper indicates why the Toll Index is immune to the market share of road transportation vs. air, rail or waterways. We should make clear that the Toll Index is a new type of index, which is not meant to forecast the Production Index but to give us a reliable early nowcasting of the state of the economy in general. We think of it literally as innovation based economic telemetry.

${ }^{2}$ The Toll Index has been discussed in the Financial Times, in Tim Harford's blog and in Wirtschaftswoche. It is also featured in an upcoming edition of Marketplace Europe on CNN International. Information on the media coverage of the Toll Index may be found under http://idsc.iza.org/tollindex. 
The Toll Index is currently published in the last third of a month following the publication pattern of MAUT data by the Bundesamt für Güterverkehr and it is therefore the earliest available short term indicator of the German business cycle.

\section{Where to find the Data?}

Information is posted on the webpage of the International Data Service Center (IDSC) of IZA http://idsc.iza.org/tollindex.

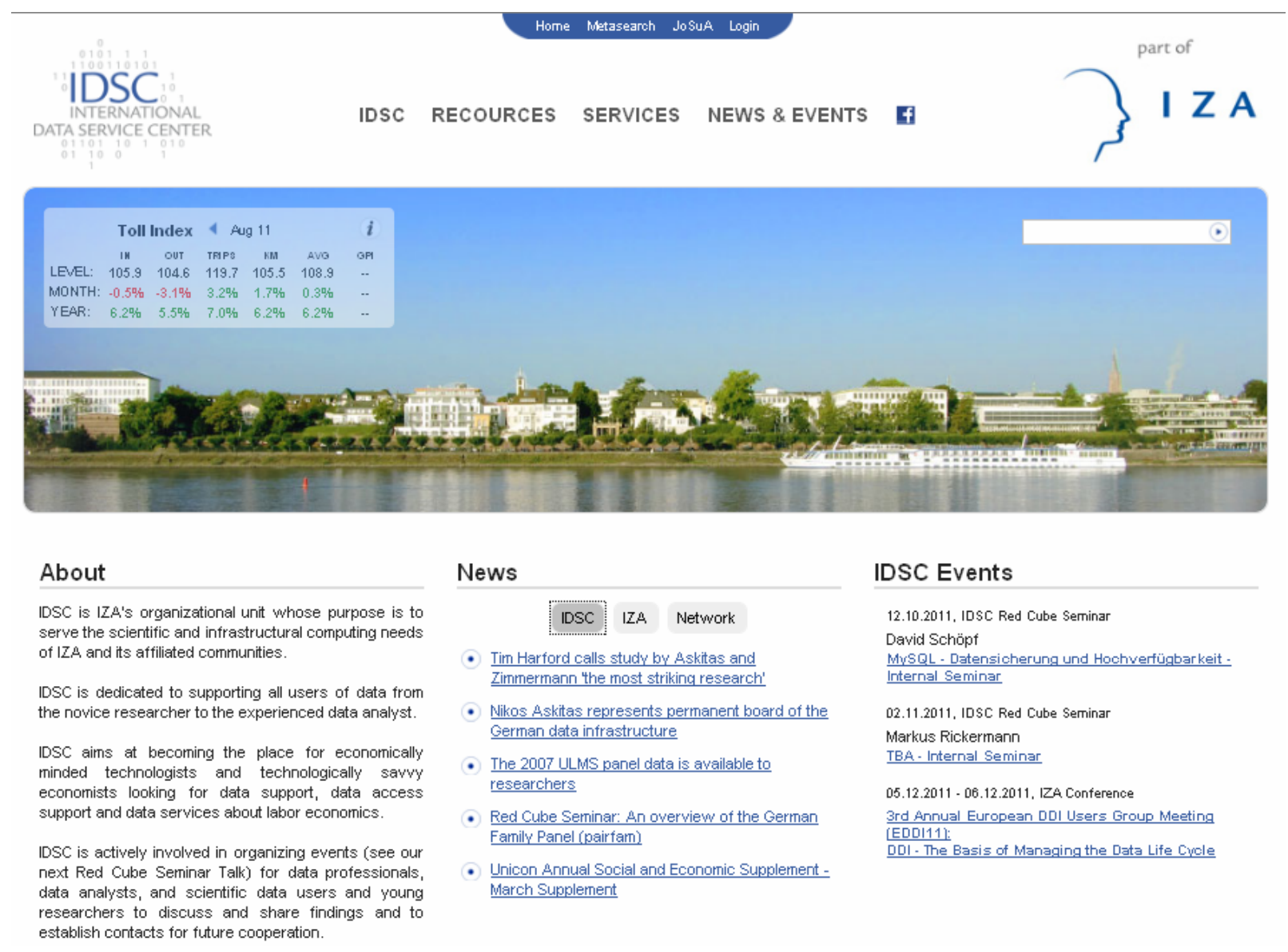

\section{Policy Discussion}

The Toll Index is a new type of live economic telemetry which will enable us to know and monitor the state of the economy in real-time. The use of the MAUT system for this purpose was 
originally unintended, but our work shows that such economic telemetry systems have in fact been long overdue.

We are confident that the Toll Index has the potential to become a standard early indicator for business cycle forecasters and policy makers. Moreover, it could become an internationally used real-time economic indicator if the MAUT system would be applied also elsewhere. In that case the TI would have the potential of reflecting bilateral trades and much more.

The MAUT system is a simple but effective application of advanced technology. Its support through the government was a successful activating industry policy or competition policy. While we cannot but praise the German government for inspired work for this world-wide unique system, we must point out that the conception of the project was narrow and far from being comprehensive. The potential of the MAUT system for the delivery of essential economic data should have been recognized early and in fact built into the data retention policy of the system (which now is rudimentary). Much more data could then have been retained which would have allowed researchers to extract much more value for society by using it.

\section{A Data Policy Agenda}

Any project in complex societies as ours is bound to produce some kind of primary or residual data. It is therefore today with good reason a standard concern that care should be taken that data privacy is not violated when it comes to the use of data of individuals. However, it should become equally standard to engage empirical social scientists in order to optimize data retention for scientific purposes. From a societal point of view this is nothing but an optimization of return on investment. In short,

\section{secondary data use should become a primary concern.}

As our example shows policy makers should invest in better and faster data collection in order to help forecasting practitioners produce more reliable results. Given today's computing and networking capabilities our impaired ability to nowcast the state of the economy can definitely improve. It would perhaps be fitting with the times if the German government would 
take the initiative to export the underlying MAUT technology to other countries in particular in Europe and thus contribute to better data on a European level on the one hand and to more European integration on the other.

\section{Reference}

Nikos Askitas \& Klaus F. Zimmermann, Nowcasting Business Cycles Using Toll Data, IZA Discussion Paper No. 5522, forthcoming in: Journal of Forecasting, 2011. 